International Journal of Social Sciences and Humanities
Available online at www.sciencescholar.us
Vol. 5 No. 2, August 2021, pages: $92-98$
e-ISSN: 2550-7001, p-ISSN: 2550-701X
https://doi.org/10.29332/ijssh.v5n2.826

\title{
Intra-Family Conflict in Nepal: Result of a Game Between Doing and Getting Done
}

Durga Bhusal a
Manuscript submitted: 09 March 2021, Manuscript revised: 27 April 2021, Accepted for publication: 18 May 2021

intra-family conflict;

tra-family conflict,

manifest conflict;

perceived conflict;

International Journal of Social Sciences and Humanities (C) 2020.

This is an open access article under the CC BY-NC-ND license (https://creativecommons.org/licenses/by-nc-nd/4.0/).

\section{Contents}

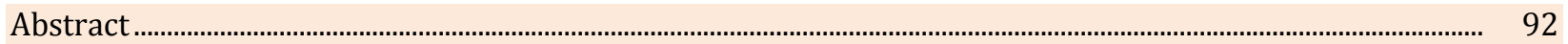

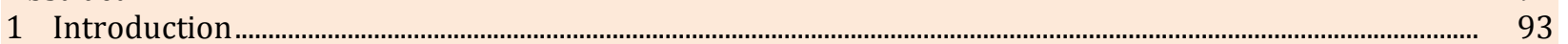

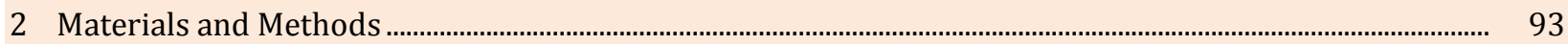

3 Results and Discussions ................................................................................................................................................. 93

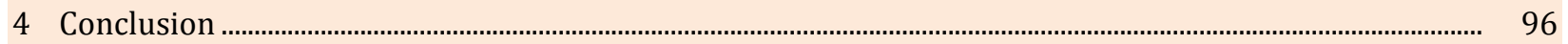

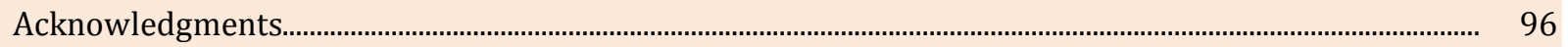

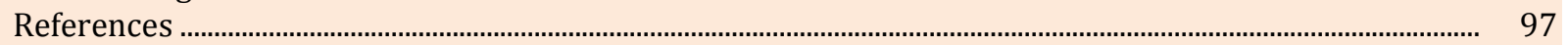

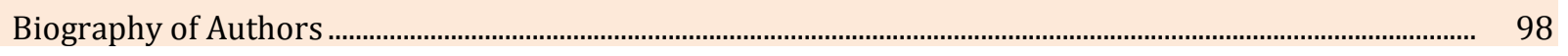

a Butwal Multiple Campus, Tribhuvan University, Nepal 


\section{Introduction}

The true sense of belonging and togetherness can be provided by a functional family structure. Conflict situation in a family differs from the conflicts in a community or national level. The emotional attachment among the members of a family is disrupted because of several reasons. Some conflict thinkers present that one of the unavoidable parts of all human connotation is conflict (Adams, 1966; Coser, 1956; Dahrendorf, 1959; Sprey, 1969). Failure to adapt to changing environments, and corrosion of the bond of collective harmony occur due to suppressed conflict amassing hostility (Straus, 1979). Females along with children are believed to be more carefully supervised to control than males (Norland et al., 1979), and females are more forcefully integrated into home life than males qualified to become independent of the family and to concern themselves with outside activities (Toby, 1957). Sociologists believe that family relationships are more important for the delinquency of females than for the delinquency of males (Monahan, 1957; Toby, 1957). Prior history of abuse can increase the likelihood of abusive behavior, and parental conflict and aggression, or a conflict home atmosphere are related to crimes of offspring (Njenga, 2016).

Nepal witnessed the harmful effects of conflict on children are reflected in the long history of research documenting the positive relationship between interparental conflict and child adjustment problems. Couple conflict is related to poor outcomes of children across different family structures due to the results on divorced and separated. Children growing in more persistent circumstances of interparental conflict may be at risk for developing behavior problems because of the experiences stimulated by negative interactions (Ingoldsby et al., 1999).

\section{Materials and Methods}

The purpose of this paper is to deliver a viewpoint on Intra-Family Conflict in Nepal. To fulfill the target of this paper author has attempted to introduce the result of a game between doing and getting done. Various empirical studies and established knowledge have been integrated to indicate the potentiality of the target. Secondary data are described to clarify the aim of this paper in which previous studies were consulted for in-depth knowledge on the topic under study. No, any statistical technique is applied to put the viewpoint. The main objective of this review is to reflect the situation created by the intra-family conflict in Nepal. This article sheds the light to get the responses on the request "Does the conflict between 'doing and getting done' help the family always be deteriorative?". The study used qualitative methods whereby individual interviews and participatory involvement were executed.

\section{Results and Discussions}

Family members express their emotions differently (Tagiuri \& Davis, 1996), and family members are more likely to express negative than positive emotions (Efendy, 2013). Because of their overlapping memberships in a family, working in the family they can have three simultaneous roles: as relatives, they are concerned primarily with the welfare and the unity of the family, as owners they are interested in return on investment, and as managers, they are interested in operational effectiveness. The emotional content of the bond of family members is due to the potential of love and hate among them and it often exteriors more easily but tough to infer the activities of one another (Tagiuri \& Davis, 1996). According to the feminist theory, intra-family conflict is a manifestation of gender-based domination promoting rigid roles in family and society, which limits the economic opportunity for women (Njenga, 2016; Crowell et al.,2014; Ladd \& Murray, 2001).

\section{Conflicting parties}

The conflicting parties can be categorized into three levels. First, the interpersonal or dyadic conflict occurs between two persons. Second, the individual-subgroup conflict occurs between an individual and a subgroup of family members. Third, inter-subgroup conflict happens between subgroups of family members. Based on

Bhusal, D. (2021). Intra-family conflict in Nepal: result of a game between doing and getting done. International Journal of Social Sciences and Humanities, 5(2), 92-98. https://doi.org/10.29332/ijssh.v5n2.826 
the generational relationships, intragenerational and intergenerational conflicts have emerged. Recurrent of the familial conflict is more between different generational members than that in the same generation. and the intergenerational differences can lead to generational conflict. It can be seen that generational conflicts in a family are more likely to occur base on perception when the ability or attitude of one generation does not fit with the other. Hence it can be said that the perception gap may encourage intergenerational conflict. Senior members perceive junior members as lacking inexperience, and the younger generation perceives their seniors as reluctant to change. Besides this kind of perception, intergenerational conflict generally occurs when the older generation does not delegate decision-making authority, and implementing ideas to the younger. Ages, tenures, managerial experiences, and educational backgrounds help to defend the opinions and work to raise the conflict. The existence of generational perception gaps over managerial capability increases the occurrence of cross-generation conflicts (Efendy, 2013).

\section{Conflict generating relationship}

Three types of conflict-generating relationships are identified as interest-group relationships, superiorsubordinate relationships; and working relationships (Pondy, 1967). The entire relationship can be characterized by certain stable aspects of conditions, affect, perception, and behavior. Five stages of a conflict episode are identified: (1) latent conflict- it rises in three conditions- competition for scarce resources, autonomy drives, and goal divergence, (2) perceived conflict-it results from the misunderstanding of each other's true position when no conditions of latent conflict exist, (3) felt conflict- the aspect of effect that results from identity crises, or extra work pressure, (4) manifest conflict- the motivational behavior towards open aggression, and norms tend to be expressed in proscribed physical and verbal violence, and (5) conflict aftermath- the condition of a conflict that is merely suppressed and results in more serious form than in the latent condition until resolution or dissolution of the relationship. However, Greenfield \& Yan, (2006) state that conflicts can provide an opportunity for new learning and an improved connection between the relationships. The contrary nurturing environment of the family towards children is likely to grow the situation for the generational conflict.

\section{The conflict between doing and getting done}

In the Nepali culture particularly in the Brahmin family, the member of a family who does not work self but gets done from other members seems like the head of the family. The individual mobilizes the earning of other family members. The underneath interest of the member is to eat well and wear fine to be looked at as smart maintenance. Transparent mobilization of earning becomes weaken due to the unfair behavior of the headlooking person of the family. His dominating behavior spreads the seed of intra-family conflict. On the other hand, the family member who earns may not have the time to be tip top and smart because of his/her busy schedule of work. The earner submits the total earning to the head of the family based on the understanding of being a good member of the family (Yusran et al., 2017; Meyers et al., 2004; Pratiwi et al., 2019). The illustration, where earning of other receiving person and who does not earn self has the short moment of cooperative relationships in the family and becomes one of the important causes of family separation. Backbiting emerges from the bad relationship between doing and getting done and thereby increases the distance of hostility (Barki, H., \& Hartwick, J. 2004).

Failure exercise of the expenditure expected for the betterment of doing work of increasing earning to the future quality life also becomes the cause of intra-family conflict. Dominating behavior of 'doing' person who acts also as 'getting done' may be the conflict generating cause. Once a neighbor and teacher of the author had shown the same incident. For instance, one elder brother in his family, the main earner of the family, had told the author who is his student of primary school in the response to a request in a meeting that how did you decide to separate the family: "I ordered my junior brother to bring meal material from the Floor Meal. The junior replied that he could not go to do so because of his torn lower underwear. He had to go through crossing a stream. At the time, if he would have gone to do the work, he should have taken off his pant to cross the stream of the rainy season. Putting off the pant, his torn underwear would be opened to see my outers. At the same time, my father also added the conflict-generating subject matter and said that you did not be aware of the need of the family-like what 
kind of clothes the family members are wearing. The situation grew on bad conversation, and my junior brother did not go to do the work. Finally, we decided to separate living."

\section{Field Note}

The researcher as a passive listener of an interesting conversation of two senior citizens of 60 and 65 years old in a social gathering was observing them collect valuable information about the evolution of conflict. Generation gap on the relationship between foreign job holder and parents at home in a clear figure that was obtained from the two senior citizens in conversation who are reviewing their life events. ' $\mathrm{A}$ ' of 60 was coresident of son together and B of 65 whose son was in the foreign job. For a moment, B was denying the saying of $A-$ togetherness of offspring is true happiness during the later life-, where B is pleating the importance of money. In the conversation, they meet at the stage of the competition and A put his thought loudly that togetherness of son whether he earns more or not is better than the sent large amount of money from the foreign job or business of the son. A senior citizen friend of B said let's try and contacted the son of B in foreign and says, "your father is seriously ill, and you must come home as soon as possible". The son replied to the friend of his father that uncle may I come now or later. I can attend once but not both the time. If I came now cannot come later and vice versa. More clearly, if the son came home to meet his ill father and father did not expire during the determined time, he has to return to his job, and secondly, he cannot come home even after the demise of his father for the mandatory ritual (Teoh \& Foo, 1997; Koziarski et al., 2016). Then B agreed on the fact. The desire of parents is may the offspring live with them and eat together, and participate the sorrow and happiness together, but the offspring who are far from the native culture think differently. This type of conversation helps to learn the chapter that how does the conflict even in the happy family evolves from the conversation between intimate friends, and teaches the thought disparity between the tips of the generation gap.

Towards the part of the conflict resolution, senior applies the strategies of dominating, compromising, or integrating with younger- their counterpart of conflict. More assertive or less cooperative behavior cannot communicate positive emotions and cause conflict. Sometimes avoidance of frontal conflict may lead to reach the target of resolution. For instance, an incident between father and son about fixed asset mobilization to get a higher income, son proposed for, but the disagreement of the father was marked by the anger face. The son was not motivated by the response of his father. He conversed with his proposal again and wanted approval when his father was calm. This incident was clearly described by the son as: "When I said that asset mobilization can multiple our income. My father said to me not to be presumptuous, but to do a bit riskless business for the betterment of the future. He denied my proposal and was in a very angry mood. I said nothing and went outside to be fresh. I avoided frontal conflict. In the next few days, I met him with the same proposal when he was calm. We discussed it again with a more detailed work plan. Finally, I convinced my father, and we came up with a mid-way solution."

\section{Conflict as the result of a game}

Curiosity has lately grown up in the submission of game theory to explain various difficulties in the field of social science. The game theory by its concepts and results is more philosophical non-quantitative parts of social science. The basic ingredient of a society is the interaction of individual entities. Interaction demands at least two parties, and accordingly, if competition exists, there is a game perceived with the intention of victory. In the case of intra-family conflict, if consensus does not stand between the members of a family on the view presented, interaction occurs putting own view to a certain subject matter. Game theory is a mathematical approach to the modeling of human interaction in groups and societies to analyze the situation in which two or more individuals make decisions (Trockel, 2004). The exercise to win the debate can be understood as a game. Interaction in dominating behavior differs from the interaction for collaboration of work. Attempt to be superior through said or unsaid manner is carrying a work plan of victory. Opposing interest to accept the subject motivates to design the circumstances of interaction which may turn into conflict. Cultural practices act as the rule of a game in intra-family interaction between members acting as the players. Sometimes conflict separates the players not to play forever. The game between 'doing' and 'getting done' in a family seems at the first glance there is not any game but we get through the in-depth study of the incident there will be hidden competition moving towards

Bhusal, D. (2021). Intra-family conflict in Nepal: result of a game between doing and getting done. International Journal of Social Sciences and Humanities, 5(2), 92-98. https://doi.org/10.29332/ijssh.v5n2.826 
conflict. Then the author is convinced to present knowledge from scholars that the tactical interrelationship is the spirit of game theory (Jayantilal et al., 2016).

\section{Conclusion}

A large number of people fear conflict and they attempt to sidestep it. This study concludes and suggests that more research is needed in the measurement of emotional and behavioral reactivity in an intra-family relationship, the relations with interparental conflict, and the development of behavior problems in family members and particularly in newly growing children. Conflicts provide not only an unfair connection but also can provide an opportunity for new learning and an improved connection between the relationships. No two individuals are the same but maybe similar in most of the features. Thereby they may have individual difference because of values and needs they accepted that leads to conflict. Interdependence creates the field for interaction and the interaction leads to conflict. Intra-personal conflict helps the individual to improve performance over time. The conflict based on emotion, not on facts is effective which is more negative than substantial in the family relationship which is underneath of unsaid game. Accommodation of conflict between doing and getting done is the potential game for the way of win-win resolution.

\section{Acknowledgments}

I am grateful to two anonymous reviewers for their valuable comments on the earlier version of this paper. 


\section{References}

Adams, B. N. (1966). Coercion and consensus theories: Some unresolved issues..

Barki, H., \& Hartwick, J. (2004). Conceptualizing the construct of interpersonal conflict. International journal of conflict management.

Coser, L. A. (1998). The functions of social conflict (Vol. 9). Routledge.

Crowell, S. E., Baucom, B. R., Yaptangco, M., Bride, D., Hsiao, R., McCauley, E., \& Beauchaine, T. P. (2014). Emotion dysregulation and dyadic conflict in depressed and typical adolescents: Evaluating concordance across psychophysiological and observational measures. Biological psychology, 98, 50-58. https://doi.org/10.1016/j.biopsycho.2014.02.009

Dahrendorf, R. (1959). Class and conflict in industrial society. Stanford University Press..

Efendy, K. I. (2013). The nature of intra-familial conflict in large-scale privately-held family businesses in Indonesia (Doctoral dissertation, Queensland University of Technology).

Greenfield, P., \& Yan, Z. (2006). Children, adolescents, and the Internet: A new field of inquiry in developmental psychology. Developmental psychology, 42(3), 391.

Ingoldsby, E. M., Shaw, D. S., Owens, E. B., \& Winslow, E. B. (1999). A longitudinal study of interparental conflict, emotional and behavioral reactivity, and preschoolers' adjustment problems among low-income families. Journal of abnormal child psychology, 27(5), 343-356.

Jayantilal, S., Jorge, S. F., \& Palacios, T. M. B. (2016). Effects of sibling competition on family firm succession: A game theory approach. Journal of Family Business Strategy, 7(4), 260-268. https://doi.org/10.1016/j.jfbs.2016.10.001

Koziarski, A., Kissui, B., \& Kiffner, C. (2016). Patterns and correlates of perceived conflict between humans and large carnivores in Northern Tanzania. Biological Conservation, 199, 41-50. https://doi.org/10.1016/j.biocon.2016.04.029

Ladd, H. F., \& Murray, S. E. (2001). Intergenerational conflict reconsidered: County demographic structure and the demand for public education. Economics of education review, 20(4), 343-357. https://doi.org/10.1016/S0272-7757(00)00058-3

Ma, S. (1979). Measuring intra family conflict and violence: The conflict Tactics Scale. J Marriage Family, 41, 7588.

Meyers, F. J., Linder, J., Beckett, L., Christensen, S., Blais, J., \& Gandara, D. R. (2004). Simultaneous care: a model approach to the perceived conflict between investigational therapy and palliative care. Journal of pain and symptom management, 28(6), 548-556. https://doi.org/10.1016/j.jpainsymman.2004.03.002

Monahan, T. P. (1957). Family status and the delinquent child: A reappraisal and some new findings. Social forces, 250-258.

Njenga, E. N. (2016). Factors Influencing Intra Family Conflicts: A Case Of Kikuyu Sub County, Kiambu County, Kenya (Doctoral dissertation, University of Nairobi).

Norland, S., Shover, N., Thornton, W. E., \& James, J. (1979). Intrafamily conflict and delinquency. Pacific Sociological Review, 22(2), 223-240.

Pondy, L. R. (1967). Organizational conflict: Concepts and models. Administrative science quarterly, 296-320.

Pratiwi, I. Y., Ratnadi, N. M. D., Suprasto, H. B., \& Sujana, I. K. (2019). The effect of role conflict, role ambiguity, and role overload in burnout government internal supervisors with tri hita karana culture as moderation. International Research Journal of Management, IT and Social Sciences, 6(3), 61-69.

Sprey, J. (1969). The family as a system in conflict. Journal of Marriage and the Family, 699-706.

Tagiuri, R., \& Davis, J. (1996). Bivalent attributes of the family firm. Family business review, 9(2), 199-208.

Teoh, H. Y., \& Foo, S. L. (1997). Moderating effects of tolerance for ambiguity and risktaking propensity on the role conflict-perceived performance relationship: Evidence from Singaporean entrepreneurs. Journal of business Venturing, 12(1), 67-81. https://doi.org/10.1016/S0883-9026(96)00035-3

Toby, J. (1957). The differential impact of family disorganization. American sociological review, 22(5), 505-512.

Trockel, W. (2004). Game theory. The language of social science?.

Yusran, Y., Sahide, M. A. K., Supratman, S., Sabar, A., Krott, M., \& Giessen, L. (2017). The empirical visibility of land use conflicts: From latent to manifest conflict through law enforcement in a national park in Indonesia. Land use policy, 62, 302-315. https://doi.org/10.1016/j.landusepol.2016.12.033

Bhusal, D. (2021). Intra-family conflict in Nepal: result of a game between doing and getting done. International Journal of Social Sciences and Humanities, 5(2), 92-98. https://doi.org/10.29332/ijssh.v5n2.826 


\section{Biography of Author}

Durga Bhusal (Ph.D. Scholar, Tribhuvan University, Nepal in the area of
Gerontology) is currently an Assistant Professor in Butwal Multiple Campus,
Tribhuvan University, Nepal. He has 6 months of work experience as a Population
Management Facilitator in a program of Ministry of Population and Environment,
Nepal. Mr. Bhusal has more than 15 years experience of teaching Population Studies
under the faculty of Humanities and Social Sciences of Tribhuvan University. He has
authored and co-authored many national and international research articles, books,
and reports.
Email: durga.bhusal@bumc.tu.edu.np

